\title{
REVITALISASI KOMUNIKASI ANALOG DI KOMUNITAS KELUARGA MUDA INDONESIA
}

\author{
Nurul Ifadhah $^{1^{*}}$ dan Irwansyah ${ }^{2}$ \\ ${ }^{1}$ Universitas Pelita Harapan, Tangerang - Indonesia \\ ${ }^{2}$ Universitas Indonesia, Depok - Indonesia \\ *nurul.ifadhah@gmail.com
}

\begin{abstract}
Handwritting into book is the most ancient form of analog communication and a means of remote communication that was first present in human life. However, just like any other communication product, writing on books (journaling) slowly begins to be eroded by technology dermination. The culture of analog writing shifts to typing. The decline in interest analog writing is seen from the results of research and regulations in some countries that no longer require the younger generation to have certain skills of writing. In fact, analog writing activities are scientifically proven to be mentally healthy. The situation in Indonesia is slightly different from the presence of the government that requires handwritten classes for elementary children, and the growing writing market in young family communities. Journaling in the millenial mother community is a process to get a more conscious lifestyle. This research aims to understand the revitalization process of an analog communication to remain favored by people who have become accustomed to consuming communication information technology. Through the Case Study it was found that journaling as analog communication is able to maintain its existence because of the revitalization of ideas through interdisciplinary and multidisciplinary collaboration in the scope of communication science.
\end{abstract}

Keywords: analog communication; the young mother community; journaling

\begin{abstract}
Abstrak
Menulis dengan tangan ke media kertas atau buku ialah bentuk komunikasi analog paling kuno dan alat komunikasi jarak-jauh yang pertama kali hadir di kehidupan manusia. Namun, sama seperti produk komunikasi lainnya, menulis di atas kertas atau buku perlahan mulai tergerus dengan adanya determinasi teknologi. Budaya menulis secara analog bergeser menjadi mengetik di perangkat elektronik. Penurunan minat menulis secara analog terlihat dari hasil penelitian dan peraturan di beberapa negara yang tidak lagi mewajibkan generasi mudanya untuk memiliki keterampilan tertentu ketika menulis analog. Padahal, kegiatan menulis secara analog terbukti secara ilmiah bisa menyehatkan mental. Keadaan di Indonesia justru sedikit berbeda dengan hadirnya pemerintah yang mewajibkan kelas menulis tangan bagi anak sekolah dasar, dan tumbuhnya pasar menulis di komunitas-komunitas keluarga muda. Kegiatan menulis jurnal (journaling) dalam komunitas ibu muda ini diolah menjadi salah satu cara untuk mendapatkan pola hidup yang lebih berkesadaran. Penelitian ini bertujuan untuk memahami proses revitalisasi dari sebuah tindakan komunikasi analog agar tetap digemari oleh masyarakat yang telah terbiasa mengonsumsi teknologi informasi komunikasi. Melalui metode Studi Kasus ditemukan bahwa menulis di kertas atau buku sebagai komunikasi analog mampu terjaga eksistensinya karena adanya penyegaran ide melalui kolaborasi interdisplin dan multidisplin dalam lingkup ilmu komunikasi.
\end{abstract}

Kata Kunci: revitalisasi komunikasi analog; komunitas keluarga muda; menulis jurnal

\section{PENDAHULUAN}

Hari ini manusia telah memasuki fase di mana informasi menjadi sebuah kebutuhan utama yang selalu diakses setiap harinya.
Proses penyampaian informasi pun kini dilakukan secara analog ataupun termediasi. Komunikasi analog merupakan pertukaran pesan dan makna antara komunikator dan 
komunikan secara langsung tanpa melalui perantara (Straubhaar, Tufekci Zeyned, \& Rojas, 2012), sementara komunikasi termediasi dikemas dalam beragam medium, seperti, Televisi, Radio, dan Media Sosial.

Berbicara mengenai masyarakat dan perangkat komunikasinya, sosiolog asal Spanyol Castells \& Cardoso dalam (Brocke \& de Marco, 2016), memaparkan teori bahwa dunia manusia selalu mengalami transformasi struktur yang multidimensi, dan baginya dimensi dari paradigma teknologi sangat memengaruhi masyarakat, terutama perkembangan teknologi di bidang informasi dan komunikasi. Teknologi yang merupakan perpanjangan indera manusia memegang peranan besar dalam membangun peradaban masyarakat.

Korelasi antara peradabaan masyrakat dan teknologi sudah banyak dipaparkan dalam kajian ilmiah. Pandangan paling populer terkait perkembangan manusia dan teknologi komunikasi dikatakan oleh (McLuhan, 2013) sebagai sebuah konsep Desa Global. Dunia digambarkan sebagai sebuah desa yang besar, dalam kehidupan manusia di Desa Global tidak ada lagi batas waktu, jarak dan tempat yang jelas. Mengandalkan teknologi internet, Informasi dapat diketahui dari satu tempat ke belahan dunia lain dalam tempo yang sangat cepat. McLuhan memperkirakan pada saatnya nanti, manusia akan sangat bergantung pada teknologi, terutama teknologi untuk komunikasi dan informasi. Pola produksi, distribusi, dan konsumsi pesan yang manusia jalani sekarang ini sudah diperdiksi oleh McLuhani sejak abad ke-20.

Desa Global muncul dikarenakan penyebaran informasi yang sangat cepat dan berlimpah di masyarakat. Penyebaran informasi yang cepat dan deras ini menggunakan teknologi informasi dan komunikasi sebagai bentuk media massa. McLuhan telah memperkirakan bahwa pada masa itu, manusia akan lebih memilih komunikasi audiovisual yang informatif, ateraktif, dan menghibur. Gagasan tersebut bisa jadi sesuai dengan kondisi manusia sekarang yang lebih menyukai bentuk komunikasi interaktif yang terdemiasi teknologi.

Namun, apa yang telah McLuhan paparkan tidak sepenuhnya benar. Di tengah aruh teknologi informasi yang begitu deras dalam tatanan masyarakat informasi, ada satu jenis komunikasi analog yang mampu bertahan melalui proses revitalisasi, yaitu, menulis buku di junal atau journaling. Walaupun aktivitas menulis di media kertas ataupun buku telah bergeser menjadi aktivitas mengetik di perangkat elektronik; laptop, computer, dan ponsel, kegiatan menulis dengan tangan ke dalam buku mengalami konseptualisasi baru melalui ide journaling.

Kegiatan journaling mampu mendapatkan atensi masyarakat khususnya para Ibu dan keluarga muda melalui pendekatan kesehatan mental. Gagasan diungkapkan oleh seorang psikilog klinis yang kerap mengangkat isu seputar pola hidup berkesadaran (mindful living) dan conscious parenting, (Tsabary, 2016) menyatakan bahwa menulis buku bisa membawa perubahan positif, "Everyone is a manifestation of the consciousness they grew up with and therefore, to be honored for their point on the path. So now, I write to change myself. Indeed, I am a self-help author helping herself All rest will flow from this space. The only person I seek to change is myself." Menulis yang mulanya hadir sebagai cara berkomunikasi untuk mengirim pesan, ternyata bermanfaat sebagai alat untuk meningkatkan kesehatan mental.

Mengusung semangat kesehatan mental ini, kegiatan menulis ke dalam buku mampu bertahan ditengah determinasi teknologi komunikasi interaktif. Kini, kegiatan menulis buku bukan hanya sebagai medium penyampain pesan karena telag hadir melalui bentuk invoasi yang menyegarkan hingga tetap diminatai oleh masyarakat.

Penulis menyajikan penelitian terkait kegiatan menulis jurnal (journaling) sebagai tindakan komunikasi yang mampu membentuk kesehatan mental manusia; khususnya Ibu dan keluarga muda di Indonesia, dengan tujuan untuk lebih memahami proses revitalisasi dari 
sebuah medium komunikasi analog agar tetap bertahan di kalangan masyarakat informasi yang telah terpapar teknologi komunikasi. Hasil penelitian diharapkan mampu membawa informasi seputar langkah-langkah ilmiah dalam melakukan penyegaran tindakan komunikasi analog yang sebetulnya membawa banyak manfaat untuk masyarakat luas agar tetap diminati di tengah determinasi teknologi informasi.

Teknologi dan manusia hidup berdampingan, karakteristik teknologi yang selalu maju (step forward) bisa menawarkan kehidupan masa depan yang lebih baik.

McLuhan (2013) membagi sejarah peradaan manusia berdasarkan kapasitas pola komunikasi yang diadopsinya, sebagai berikut: (1) Periode Tribal. Budaya ucap atau lisan (praliterasi) sangat mendominasi perilaku komunikasi manusia pada saat itu. Indera pendengaran memegang peranan penting dalam proses komunikasi ini. Di mana pembicaraan dari mulut ke mulut menjadikan manusiamanusia yang menggunakannya sebagai sebuah komunitas yang kohesif. (2) Periode Literatur. Penemuan alfabet fonetis telah digunakan oleh manusia sebagai simbol- simbol untuk menyampaikan pesan secara tertulis tanpa interaksi face-to-face atau tatap muka. Penggunaan indera penglihatan sangat penting disertakan dalam proses komunikasi ini. Melalui kegiatan membaca tulisan memudahkan masyarakat untuk mendapatkan informasi, membaca pun mulai tumbuh menjadi sebuah budaya. Sifat komunikasi periode ini adalah liniear. (3) Periode Percetakan. Ditandai dengan ditemukannya teknologi mesin cetak oleh Johann Gutenberg, maka manusia pun memasuki periode percetakan. Penulisan teks secara masif dan massal hadir di media massa yang didistribusikan ke masyarakat, material cetak dan buku-buku bisa diakses oleh semua orang, sehingga produksi tulisan yang terjadi dengan massal ini mampu membentuk homogenitas dalam masyarakat dikarenakan adanya pengiriman pesan yang sama kepada semua orang. Sifat komunikasi di periode ini masih bersifat linier. Dilihat dari proses konsumsi pesan, pada periode ini manusia sudah tak perlu untuk berada berdekatan secara fisik guna bertukar pesan, namun manusia menjadi terfragmentasi karena seperti diisolasi. (4) Periode Elektronik. Penemuan teknologi komunikasi berupa telegraf menjadi sebuah transisi besar bagi masyarakat, dan menjadi tanda hilangnya fragmentasi masyarakat. Jarak yang jauh sudah tidak perlu dirasakan dan menjadi hambatan untuk berkomunikasi pada dalam periode ini, sehingga hubungan dan jarak antar satu manusia dengan manusia lainnya bisa terasa sangat dekat. Televisi yang hadir sebagai media informasi yang banyak dikonsumsi masyarakat kala ini, membuat penonton televisi seolah-olah berpetualang dan berada di belahan bumi yang lain, dan tidak hanya itu karena penonton dapat menyaksikan secara langsung realitas yang berbeda dari diri mereka yang terjadi di sana. Kecanggihan teknologi dalam proses komunikasi ini memerlukan pemanfaatan kinerja inderawi secara berkesinambungan dan maksimal, untuk membangun budaya lisan, budaya melihat, budaya membaca dan budaya mendengar dapat terintegrasikan dengan maksimal.

Adanya perubahan periode masyarakat berdasarkan perkembangan media komunikasi ini menunjukan bahwa dimensi teknologi yang mengatur peradaban manusia. McLuhan (2013) memperkenalkan istilah Determinasi Teknologi (Technology Determination) sebuah konsep tentang pengaruh teknologi dalam membentuk, merubah kehidupan masyarakat, termasuk cara manusia berkomunikasi. Pola komunikasi dalam tatanan sosial masyarakat juga sangat mempengaruhi budaya yang ada di dalamnya, Littlejohn, Foss, \& Oetzel dalam bukunya mengatakan "Where once technology was and instrument in the hands of humans, it now often is a means of communication, but more often than not, it's a way to occupy time and simply connected, rather than to achieve communication with another person," (2017, p. 200). Budaya manusia memang dibentuk oleh cara kita berkomunikasi yang dipengaruhi oleh eksistensi teknologi. 
Dalam dunia modern, determinasi teknologi hadir untuk meyakinkan kaum spektis yang menentang perkembangan pengetahuan berlandaskan hubungan sebabakibat. Seorang peneliti ilmu komunikasi, Paul S.Adler (dalam Allan, 2015), menjelaskan ada tiga elemen kunci dalam determinasi teknologi, yaitu : (1) Determinasi, dalam kajian teknologi hadir dalam bentuk keras (harder) dan lunak (softer). Dalam perdebatan tentang determinasi teknologi, perbedaan ini menitikberatkan tentang efek teknologi dan penyebabnya. Dalam penilaiannya tentang efek teknologi, teknologi determinasi lunak berargumen bahwa teknologi sebagai salah satu kekuatan penting, sementara terknologi determinasi keras berpandangan bahwa teknologi merupakan pendorong utama atau satu-satunya yang paling terasa atau signifikan. Sementara itu, ada juga pandangan anti determinasi teknologi ini yang menegaskan bahwa karakter teknologi ialah netral, (2) Teknologi hadir sebagai alat (equipments) dan bersifat netral dalam sebuah sains, dan merupakan sebuah sains atau pengetahuan yang mengikat objek-objek (artefak), (3) Teknologi determinasi, kehadirannya merubah tatanan masyarakat yang mengakibatkan konfigurasi struktur sosial-ekonomi: mulai dari feodalisme ke kapitalisme, perubahan struktur kerja dan keterampilan pekerja di abad ke-20, munculnya era pasca-industrialis pasca Perang Dunia II,"pasca-Fordisme," dan era globalisasi. Bagi beberapa orang, kemajuan teknologi mewakili janji emansipasi umat manusia secara bertahap.

Pergerakan teknologi yang dinamis juga dipicu oleh maraknya kapitalisme. Faktor sosial yang membentuk teknologi sangat bergantung pada konteks sosial, bahkan sangat mungkin determinasi teknologi ini hadir dalam beberapa bentuk spektrum ideologi yang eksis di masyarakat.

Menyikapi argumentasi tersebut (Pinch, Hughes, \& Bijker, 2014) memperkenalkan konsep Social Construction of Technology (SCOT) yang membingkai hubungan antara perkembangan teknologi dengan kultur dalam tatanan sosial disekitarnya. Dalam konsep
SCOT, teknologi diidentifikasi hadir dalam memberikan pilihan kepada manusia dan teknologi didayagunakan untuk memudahkan kehidupan masyarakat.

Dengan kemunculan media baru berbasis teknologi digital yang menampung informasi di ruang virtual, apakah menggerus model komunikasi konvensional? Bagaimana medium komunikasi berbasis analog bertahan di era disrupsi informasi seperti sekarang? Padahal, seperti yang diungkapkan oleh Sherry Turkle dalam buku A First Look of Communication Theory (Griffin, Ledbetter, \& Sparks, 2019) bahwa komunikasi berbasis teknologi ataupun digital akan mengurangi rasa intim dan empati dibanding ketika manusia melakukan interaksi tatap muka - komunikasi konvensional.

Mengacu pada teori Extension of Human Faculties yang menyatakan bahwa teknologi merupakan hasil dari ekstensi atau perluasan dari kemanusiaan seperti perpanjang indera dan saraf manusia ke dalam berbagai macam media (McLuhan, 2013). McLuhan memaparkan analog memiliki keterkaitan dengan artefak yang memiliki hubungan yang linear atau terletak pada sebuah garis lurus dengan ekstensi. Organ tubuh manusia salah satunya ialah media yang merupakan ekstensi dari fungsi kognitif manusia. Dia mengatakan teknologi saat ini mulai bergerak dari teknologi mekanik menjadi teknologi listrik (lebih dikenal dengan istilah analog dan digital).

Melalui teori tersebut, dapat ditarik sebuah definisi tentang komunikasi analog, adalah segala kegiatan komunikasi yang melimatkan kinerja indera dan motorik manusia. Ketika manusia berbicara dan menulis, terlepas melalui medium apa yang digunakan ketika melakukannya, sesungguhnya manusia sedang melakukan komunikasi analog.

Komunikasi analog adalah "Analog communication uses continuously varying signals corresponding to the light or sounds originated by the source" (Straubhaar, LaRose, \& Davenport, 2016). Dapat dijabarkan secara sederhana bahwa proses pertukaran pesan dan 
makna dari komunikator ke komunikan secara langsung tanpa melalui channel adalah komunikasi analog.

Salah satu jenis komunikasi konvensional lainnya yang berbasis analog dan hampir kehilangan popularitasnya adalah menulis tangan di buku. Kehadiran teknologi seperti komputer dan ponsel mulai merubah pola menulis manusia, semula melakukanya di kertas ataupun buku menjadi aktivitas mengetik di perangkat elektronik. Seperti yang terlapor di (Dailymail.uk, 2012) penelitian yang pernah dilakukan di Inggris terhadap 2.000 orang oleh Docmail, sebuah perusahaan percetakan dan pengiriman surat, setidaknya satu dari tiga responden belum menulis apa pun dengan tangan dalam enam bulan sebelumnya. Ratarata mereka belum menuliskan pena ke kertas dalam 41 hari sebelumnya.

Hasil penelitian ini mendukung temuan dalam kehidupan sehari-hari bahwa dengan teknologi komunikasi informasi, manusia bisa menulis dengan cepat sehingga salinan tulisan tangan mulai jarang dilakukan. Padahal banyak temuan ilmiah yang mengemukakan bahwa kegiatan menulis dinilai baik untuk kesehatan mental. (Thoele, Gunalp, \& Baran, 2020) mengatakan bahwa proses ekspresi diri melalui tulisan, memiliki efek menguntungkan secara psikologi karena bisa menurunkan level kecemasan. Saleh Abbas dalam (Ratna, 2017, p.97) juga menyatakan bahwa menulis adalah sebuah keterampilan dalam menuangkan pikiran, pendapat, gagasan, tanggapan, ataupun pernyataan melalui penggunaan bahasa tulisan. Kegiatan menulis adalah sebuah medium ekspresi diri yang dapat menyehatkan mental, dan merupakan bentuk komunikasi yang sudah ada sejak peradabaan awal manusia.

Sejarah menulis, seperti yang ada dalam artikel di (Kompas.com, 2020) adalah sebagai pengejewantahan dari bahasa tutur atau lisan. Menulis diperkiran sudah dikembangan oleh Bangsa Sumeria sejak 35.000 SM (Sebelum Masehi) sebagai medium komunikasi jarak jauh yang diaplikasikan dalam aktivitas perniagaan. Pada saat itu, penting untuk mengembangkan sebuah alat komunikasi jarak jauh dikarenakan meningkatkan jumlah kota di kawasan Mesopotamia namun kebutuhan sumber daya menyusut sehingga kegiatan berniaga jarak jauh penting untuk dilakukan. Medium penulisan adalah dengan penggunaan batu, setelah itu munculnya penemuan papirus oleh masyrakat dari Mesir sekitar tahun 3000 SM. Ketika itu, tanaman papirus, sejenis ilalang yang tumbuh di sepanjang lembah Sungai Nil dikaryakan dalam bentuk lembaran-lembaran kertas saat ini oleh bangsa Mesir.

Data dari (www.worldhistory.org, 2011), dapat membuktikan sejarah tersebut melalui eksistensi dari lukisan gua pada periode Manusia Cro-Magnon antara tahun 50.000 30.000 SM yang mendeskripsikan kehidupan manusia sehari-hari. Lukisan tersebut menggambarkan sebuah bahasa, dan beberapa gambar yang menceritakan sebuah kisah, bukan hanya semata-mata lukisan binatang dan manusia.

Model tulisan paling awal yang dipakai adalah pictographs atau piktograf, artinya simbol yang mewakili obyek. Simbol ini dipakai untuk membantu manusia ketika melakukan kegiatan berniaga; mengingat apa saja yang perlu dibeli, dan apa-apa saja yang sudah dikirim. Selain itu, piktograf, juga bisa digunakan sebagai catatan untuk pengalokasian barang yang diperlukan, atau jenis barang yang akan dibeli dan dijual. Piktograf ini ditulis di atas tanah liat yang basah lalu kemudian dikeringkan. Alat ini menjadi catatan resmi perdagangan di masa tersebut. Namun, walaupun menjadi alat resmi, catatan piktograf hanya berisi seputar barang dan benda yang diperdagangkan. Sehingga hasil dari Piktofraf tersebut tidak menjelaskan secara detail. Oleh sebab itu, untuk mengekspresikan konsep tulisan, bangsa Sumeria mengembangkan fonogram (Vann, 2020).

Bangsa Sumeria terus mengembangkan tulisan sebagai sebuah sarana komunikasi untuk mencatat peristiwa-peristiwa yang ada. Selain itu para ahli juga menciptaan suatu bentuk seni dari tulisan yang saat ini kita kenal sebagai sastra. Dimulai dengan sistem penulisan di atas tanah liat lalu dipakai ke beberapa wilayah 
sekitarnya. Hampir semua catatan sejarah yang ada sampai saat ini, berasal dari timbunan tanah liat yang tertulis dalam tulisan paku. Sistem ini dibuat oleh bangsa Sumeria dan ditemukan oleh para arkeolog dunia (Ewan, 2019).

Piktograf kemudian dikembangkan sistem penulisan yang dilengkap dengan alfabet oleh para golongan penulis kuno. Alfabet yang pertama kali dikembangkan dan diperkenalkan adalah abjad Fenisia. Dengan memakai abjad Fenesia, proses menulis menjadi lebih mudah dan dipahami.

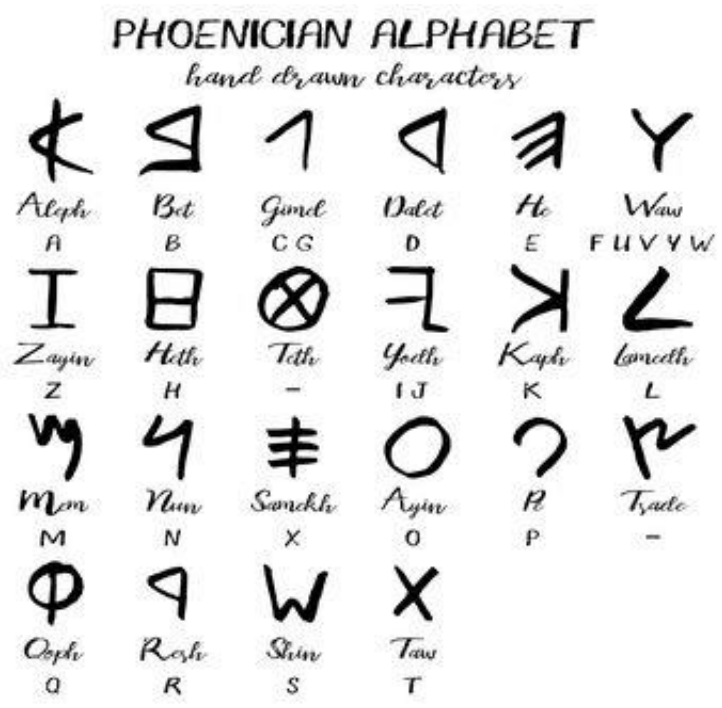

Gambar 1. Tatanan huruf pertama, Alfabet Fenisia (Sumber: Kompas.com, 2020)

Abjad Fenisia lalu berkembang ke Byblos, Sidon, Tirus, dan di setiap kota di Mediterania. Hingga kemudian, abjad Fenisia ini berevolusi menjadi tatanan bahasa tertulis dan menjadi bagian budaya masing-masing wilayah tersebut, yang akhirnya muncul penulisan Yunani dan Latin. Lalu hadir bahasa Ibrani, Arab, dan Sansekerta. Material yang dipakai untuk menulis pun kian beragam, semula yang hanya dari tanah liat, bambu yang runcing, kemudian muncul kulit binatang dan pena di Mesir, papirus Romawi dan Yunani. Kemudian kaligrafi dari Tiongkok, hingga sekarang masuk penggunaan kertas olahan dan teknologi komputer. Dalam runutan sejarahnya, menulis memang bertujuan untuk mengkomunikasikan pikiran, perasaan individu serta budaya. Selain itu, juga untuk mengabadikan pandangan dan pengalaman pada generasi penerus (Kompas.com, 2020).

Dalam jurnal (Olson, 2020) dikatakan bahwa menulis adalah ekspresi bahasa yang lebih daripada sekedar cara mentraskipkan pidato, ada tatanan bahasa tertulis untuk kebutuhan literasi. Selama awal abad ke-20, menulis dipandang hanya sebagai transkripsi, karena oleh para ahli bahasa generasi perintis seperti Ferdinand de Saussure dan Leonard Bloomfield, signifikansi konseptualnya sangat diremehkan. Baru setelah masa tersebut berlalu, menulis dipandang sebagai penyediaan media baru untuk ekspresi linguistik, lebih dari sekedar transkip retorika. Para kaum terpelajar seperti Marshall McLuhan, Eric Havelock, Walter Ong, Milman Parry, dan Jack Goody, adalah salah satu yang pertama menganalisis implikasi konseptual dan sosial dari penggunaan tertulis yang bertentangan dengan bentuk komunikasi lisan.

Selain itu definisi menulis juga dipaparkan sebagai "Writing, form of human communication by means of a set of visible marks that are related, by convention, to some particular structural level of language," (Olson, 2020, p. 1). Menulis adalah sebuah wadah mengkomunikasikan tanda dan makna ke dalam struktur Bahasa.

Ketika menjabarkan makna melalui tulisan tangan (handwritting) dibutuhkan kerjasama kemampuan psikomotorik, kognitif, dan afektif manusia. Hasil penelitian (Kiefer, et al., 2015) juga mengemukakan bahwa tulisan tangan memerlukan reproduksi bentuk setiap huruf yang dibuat secara seksama. Gerakan motorik yang terjadi dalam tubuh ketika menulis tangan ini memberikan jejak memori informatif tambahan dan dapat berkontribusi pada representasi bentuk huruf dan pengertian kalimat. Pernyataan ini sangat jelas menjabarkan bahwa menulis dengan tangan sebagai medium komunikasi sangat baik untuk daya piker manusia.

Namun, dengan determinasi teknologi yang ada di tengah masyarakat, aktivitas menulis secara analog dengan tangan mulai 
tergantikan dengan kegiatan menulis di atas layar elektronik berbasis digital atau bisa disebut dengan mengetik.

The place of handwriting has also been highly affected by the ubiquity of computers and various other screen-based writing media. A good deal of media attention in the UK was given to the decision of Finland to abandon the requirement for children to master traditional cursive handwriting. Instead, the emphasis would be on the teaching of touch typing and the most efficient way to compose a text message. To many, the ubiquity of computer and smartphone text entry seemed an inevitable pressure pushing us away from writing by hand, (Medwell \& Wray, 2017, p. 3).

Pemerintah Finlandia bahkan tidak lagi menjadikan kemampuan menulis tegak bersambung (traditional cursive handwriting) sebagai sebuah persyaratan yang wajib dipenuhi ketika anak-anak masuk ke sekolah dasar. Dalam surat kabar (thewashingtonpost.com, 2013) seorang peneliti Tulis Tangan Tegak Bersambung (Traditional Cursive Handwriting), Steve Graham, memaparkan argumen bahwa tulisan kursif, memang berada diambang kepunahan:

The truth is that cursive writing is pretty much gone, except in the adult world for people in their 60 s and 70s." He said that today's teachers value typing more than handwriting, and that by the 12th grade, about half of all papers are composed with computer word processing. "When you think about the world in the 1950s, everything was by hand. Paper and pencil," Graham said. "Right now, it's a hybrid world.

Di Indonesia menulis tangan masih menjadi mata pelajaran untuk tingkat Sekolah Dasar walaupun dalam proses belajar mengajar juga mulai menggunakan komputer. Pemerintah Indonesia hadir utuh dalam mengatur pelestarian format menulis tangan. Keputusan Direktur Jendral Pendidikan Dasar dan Menengah Departemen Pendidikan dan Kebudayaan No.094/C/Kep/I.83 mengatur bahwa anak didik wajib diajarkan menulis dalam dua tata cara yaitu dengan huruf cetak dan huruf tegak bersambung.
Tidak hanya memberikan regulasi, pemerintah juga konsiten berupaya membudayakan Cursive handwriting atau menulis huruf tegak bersambung dengan hadirnya Silabus $2013 \quad$ Pendidikan AnakSekolah Dasar 1 s.d. 3 oleh Mentri Pendidikan dan Kebudayaan yang mengharuskan anak-anak ini untuk menulis tegak bersambung dalam pelajaran Bahasa Indonesia.

Kegiatan menulis tangan tidak hanya masih mendapatkan tempat di dunia akademisi tanah air, namun secara berkala juga mulai menjadi sebuah rutinitas terapi di komunitas orangtua milenial di kota-kota besar. Hal ini tidak terlalu mengherankan karena menulis tangan ke dalam medium jurnal memang menyehatkan untuk mentalitas manusia, khususnya orangtua. Hal ini juga dikemukan dalam penelitian (Bute, et al., 2014, p. 23) khusus meneliti kegiatan menulis jurnal sebagai sebuah program terpadu dalam komunitas Ibu Hamil dan Orang Tua;

Future implementation of the journal program that incorporates the recommendations drawn from this analysis could potentially provide participants with more relevant information, promote more prolonged engagement with the journal by pregnant and parenting adolescents, and decrease any inconvenience for partner agencies.

Komunitas orangtua (parenting community) di kawasan urban Jakarta kian tumbuh sebagai wadah edukasi dan relaksasi bagi keluarga muda dari generasi milenial, sebut saja Komunitas Keluarga Nujuh Bulan, Mindtera.id, dan lain sebagainya. Rangkaian kegiatan pun dilakukan dalam komunitas keluarga muda ini, salah satunya adalah melakukan kelas menulis tangan ke dalam sebuah buku jurnal sebagai terapi berkesadaran bagi orangtua, khususnya Ibu, yang peka terhadap kecemasan, dan kelelahan menjalani kehidupan multiperan. Dalam komunitas ibu muda, kegiatan ini lebih dikenal dengan nama Journaling.

Kegiatan menulis jurnal atau journaling dalam komunitas ibu muda ini memang dipakai menjadi salah satu cara dan alat untuk 
mendapatkan pola hidup yang lebih berkesadaran. Journaling, menyimpan surat atau buku harian adalah sebuah tradisi kuno, yang berasal dari Jepang sejak abad ke-10. Orang-orang sukses sepanjang sejarah kerap menulis dan menyimpan jurnal untuk diberikan ke anak cucu mereka (Purcell, 2014).

Ada peningkatan bukti untuk mendukung gagasan bahwa jurnal memiliki dampak positif pada kesejahteraan fisik. Selain itu, (Purcell, 2014) dalam jurnalnya memaparkan penelitian dari Psikolog Austin James Pennebaker di University of Texas berpendapat bahwa jurnal reguler memperkuat sel-sel kekebalan tubuh, yang disebut Tlimfosit. Penelitian lain menunjukkan bahwa jurnal mengurangi gejala asma dan rheumatoid arthritis. Pennebaker percaya bahwa menulis tentang peristiwa stres membantu Anda berdamai dengan mereka, sehingga mengurangi dampak stres ini pada kesehatan fisik Anda. Dalam jurnalnya juga dipaparkan keuntungan lain yang bisa didapat dari kegiatan journaling sebagai berikut:

Scientific evidence supports that journaling provides other unexpected benefits. The act of writing accesses your left brain, which is analytical and rational. While your left brain is occupied, your right brain is free to create, intuit and feel. In sum, writing removes mental blocks and allows you to use all of your brainpower to better understand yourself, others and the world around you.

Pada prakteknya, kegiatan journaling sebetulnya mirip dengan kegiatan menulis buku harian. Dikutip dari website berita khusus untuk golangan orangtua (mommiesdaily.com, 2020) aktivitas journaling ini pernah sangat populer di tahun 1990-an, bagi kalangan anak sekolah atapun bangku kuliah. Pada masa itu informasi seputar biodata, kata-kata mutiara, testimoni diri dari kerabat, sticker, dan gambar goresan tinta menjadi sajian yang ditulis di dalam buku harian. Lalu, memasuki awal tahun 2000-an, trend buku harian mulai bergeser dengan wujud buku organizer. Melalui tren ini, bukan hanya buku tulis yang digemari masyarakat ketika itu, namun juga alat-alat tulisnya, mulai dari spidol warna-warni, marker, brushpen, sampai pena dengan ragam jenama juga turut ramai peminat. Salah seorang influencer dan pembuat konten Indonesia yang cukup gemar mengampanyekan kegiatan menulis jurnal, Andra Alodita mengatakan pada (chicanddarling.com, 2020)

I count my blessings and my scars, I see my hands and my feet, and then I looked around and then feel so blessed with what I have. It is indeed a process to feel content with who you are and what you have. So try giving some space to yourself. What I usually do is meditating, doing some self-care like going to the spa, getting a massage or meeting people who support me and of course, my favorite is to do journaling.

Hal serupa juga dikatakan Melissa Divaris Thompson, ahli psikoterapi holistik, mengatakan bahwa journaling dapat menjadi cara untuk menenangkan pikiran dan salah satu latihan meditasi yang dapat membantu manusia memilah emosi dan membuat prioritas dalam hidup (Popbela.com, 2021). Sementara itu, Carla Marie Manly (2021), psikolog klinis dan pakar kesehatan mental, mengatakan saat menuangkan stres ke dalam tulisan, pemicunya kadang jadi lebih dipahami. Setelah itu, seseorang biasanya akan melihat penyebab stres dengan cara yang lebih objektif dan mencoba mencari solusi. Menulis jurnal bisa menjadi latihan relaksasi guna membantu mengurangi pelepasan hormon stres seperti kortisol. Dengan begitu, sistem kekebalan tubuh semakin baik. Kegiatan menulis jurnal (journaling) teruji secara nyata sangat bermanfaat bagi kesehatan mental juga memberikan manfaat bagi kesehatan fisik

Dari kajian literatur yang sudah disajikan oleh peneliti di atas, memaparkan bahwa sudah banyak penelitian tentang journaling dalam kajian ilmu psikologi. Penelitian-penelitian tersebut memang telah menyatakan manfaat dari menulis jurnal adalah untuk kesehatan mental. Namun, masih belum ada penelitian yang mengkaji kegiatan journaling ini dalam prespektif komunikasi, teknologi, dan masyarakat.

Dalam kacamata ilmu komunikasi, kegiatan menulis jurnal adalah sebuah komunikasi 
analog yang melibatkan banyak indera manusia ketika melakukannya. Kehadiran teknologi informasi komunikasi yang bisa mendetrminasi pola konsumsi informasi masyarakat, rupanya tidak menyurutkan eksistensi jenis komunikasi menulis di jurnal ini. Justru, menulis jurnal mengalami pembaharuan secara ide dan diterima oleh komunitas keluarga muda Indonesia, khususnya Ibu dari generasi millennial dalam menerapkan pola asuh berkesadaran.

Penelitian ini dihadirkan untuk memahami proses revitalisasi dari sebuah tindakan komunikasi analog agar tetap digemari oleh masyarakat yang telah terbiasa mengonsumsi teknologi informasi komunikasi.

\section{METODOLOGI PENELITIAN}

Dalam uraian penelitian ini, penulis menggunakan metode studi kasus. Menurut Robert K. Yin (dalam Nur'ain, 2020) studi kasus adalah sebuah penyelidikan empirs terhadap fenomena kontemporer dalam konteks kehidupan nyata (real life). Yin juga memaparkan bahwa studi kasus sebagai sebuah metode penelitian dalam ilmu sosial adalah sebuah strategi ideal untuk digunakan dalam penelitian yang menggunakan pertanyaan; Bagaimana (How) atau Mengapa (Why), sedikit waktu yang dimiliki peneliti untuk mengontrol peristiwa yang diteliti, dan fokus penelitiannya adalah fenomena kontemporer, guna mencari kejadian kontemporer.

Metode penelitian studi kasus dibedakan menjadi 3 (tiga) tipe yaitu: Eksplanatoris, Eksploratoris dan Deskriptif (Yin, 2015). Dalam penelitian ini, peneliti menggunakan tipe Eksplanatoris karena pertanyaan Bagaimana dan Mengapa menjadi pondasi dasar riset. Peneliti juga lebih mengkaji pada pengarahan pemakaian strategi-strategi studi kasus, historis, dan eksperimen.

Penulis menggunakan teknik pengumpulan data dengan sumber utama adalah informan atau narasumber dari perserta kelas menulis jurnal di komunitas keluarga yang dipilih berdasarkan kerakteristik umur dan status sosial ekonomi dengan tujuan mendapatkan informasi yang relevan dengan permasalahan dalam penelitian ini. Terkait hal tersebut, dalam riset ini peneliti memakai teknik purposive sampling atau pengambilan sampel bertujuan menurut Sutopo (dalam Setyowati, 2013). Peneliti menggunakan cara pengumpulan data melalaui teknik wawancara mendalam (in-depth interview), dan observasi langsung yang berperan pasif.

Dalam menganalisa data, model yang digunakan oleh peneliti adalah Analisa Interaktif dari Miles dan Huberman (dalam Bungin, 2015) yang menyatakan bahwa kegiatan dalam analisis data kualitatif dilaksanakan secara interaktif dan berlangsung terus menerus sampai tuntas, sehingga datanya jenuh. Aktivitas dalam analisis data interaktif melibatkan tiga komponen, yaitu: redukasi data, sajian data (data display), dan kesimpulan. Ketika proses operasional penelitian, ketiga komponen tersebut saling berhubungan dan berinteraksi. Validasi data diselenggarakan melalui teknik triangulasi. L. Moleong menyatakan "Triangulasi adalah pemeriksaan keabsahan data yang memanfaatkan sesuatu yang lain di luar data itu untuk keperluan pengecekan atau sebagai pembanding terhadap data tersebut (2014, p. 330). Dalam penelitian ini, yang digunakan adalah teknik triangulasi sumber atau data, metode, dan teori.

Selain itu, penulis juga menfaatkan literature review atau studi pustaka sebagai cara pengumpulan data sekunder untuk memaparkan konsep masyarakat, masyakarat informasi, komunikasi analog, komunikasi digital, menulis tangan, journaling, terapi, dan generasi millennial. Metode studi pustaka merupakan cara upaya untuk mengidentifikasi teori dan konsep dari penelitian sebelumnya, agar hasilnya bisa memengaruhi topik peneltian yang akan dilakukan (Ridley, 2012).

Selain itu, (Sujarweni, 2014) juga memaparkan bahwa tujuan dari kajian literatur adalah untuk mengembangkan konsep yang menjadi dasar studi dalam penelitian. Penulis memilih metode ini untuk ini memungkinkan penulis menjelaskan konsep journaling dan 
komunikasi analog secara detail dan akurat sesuai pustaka yang dipilih.

Mengembangkan tema journaling sebagai terapi untuk Ibu dari generasi millennial agar lebih berkesadaraan menjalani harinya. Sementara (Nakano \& Muniz, 2018) memaparkan bahwa kajian literatur sangat sentral guna menjelaskan teori, konsep yang akan digunakan dengan batas-batas yang telah ditetapkan dalam mengokohkan argumen penelitian pada teks empiris.

Sumber data sekunder diperoleh dari buku terkait, artikel ilmiah, penelitian terdahulu, jurnal yang sudah dipublikasikan, dan juga berita di Internet sebagai pelengkap data. Melakukan pencarian dan menemukan referensi yang sama, mengkaji hubungan dari referensi dengan topik peneltian sehingga dapat memiliki dasar yang kuat dalam penelitian ini. Dengan menerapkan rangkaian proses di atas, kajian terkait masyarakat dalam kajian studi komunikasi, model komunikasi analog, menulis tangan dengan jurnal dan terapi berkesadaraan untuk ibu dari generasi millenial. Penjelasan lain tentang kajian literatur digambarkan sebagai sebuah kegiatan mengumpulkan data pustaka, membaca, hingga menyelenggarakan bahan untuk diteliti.

Penelitian ini memakai pendekatan
kualitatif yang secara deskriptif menghubungkan antara subjek dan objek penelitian sehingga dapat dikaji secara nonempirs, eksperimental atau empiris, dan teoritis. Metode kualitatif deskriptif bertujuan untuk membangun, mengembangkan, menjelaskan, dan menggambarkan kategori data yang ada (Moleong, 2018). Tahapan ini diambil untuk melihat bentuk pembaharuan atau revitalisasi menulis tangan ke dalam buku jurnal sebagai sebuah kegiatan komunikasi analog yang populer di kalangan Ibu generasi millennial sebagai media terapi untuk hidup yang lebih berkesadaran.

Berikut ialah informan-informan pada penelitian ini yang berasal dari. Beberapa komunitas keluarga muda yang melakukan menulis jurnal (journaling) dalam kegiatan keseharian mereka sebagai orangtua. Informan pertama bernama Putri, seorang ibu rumah tangga dan memiliki tiga anak laki-laki. Informan kedua bernama Rani, seorang ibu dari dua orang anak balita yang sehari-hari bekerja kantoran. Informan ketiga bernama Tita, seorang ibu yang menjalankan bisnis start up dan memiliki satu orang anak laki-laki dan satu orang anak perempuan balita. Informan keempat bernama Uti, seorang wanita yang beprofesi sebagai freelancer dan ibu dari dua orang anak balita, dan yang kelima bernama Samantha, seoarang ibu tunggal dari satu orang anak balita yang bekerja sebagai pegawai kantoran.

\section{HASIL DAN PEMBAHASAN}

Kegiatan menulis dengan tangan ke dalam medium buku jurnal, memang bukanlah hal baru. Sebelum mamasuki era digitalisasi, buku menjadi salah satu media yang paling banyak dipakai untuk menulis. Menulis adalah kegiatan komunikasi untuk menyampaikan pesan. Namun, seiring berkembangnya ilmu pengetahuan dan teknologi yang ada di dalam kehidupan bermasyarakat, menulis menjadi sebuah terapi psikologi bagi kaum dewasa, khususnya orangtua. Orangtua yang berasal dari generasi millennial menjadi golongan paling sadar untuk menjalani terapi jurnal ini.

Putri sebagai informan pertama mengatakan "Menulis keluh kesah di buku jurnal menjadi preferensi saya dibanding menulis blog yang bisa diakses oleh banyak orang. Buku jurnal bisa kita simpan di tempat pribadi yang diinginkan." (Putri, 6 Juni 2021)

Bagi Putri, menulis di medium buku jurnal memiliki nilai privasi dibandingkan menulis di blog yang berbasis digital media yang bisa diakses oleh siapapun.

Menulis gagasan ataupun curahan hati di buku jurnal rasanya sangat melegakan, karena tidak semua emosi bisa dikeluarkan secara verbal. Walaupun awalnya bingung cara mengeluarkan uneg-uneg melalui tulisan seperti apa, namun saya rajin ikut pelatihan menulis jurnal yang kini banyak disegelenggarakan oleh komunitas parenting." (Rani, 6 Juni 2021) 
Rani, informan kedua memaparkan bahwa menulis jurnal menjadi media untuk merilis emosi yang sulit ia salurkan melalui verbal. Ia pun rajin mengikuti pelatihan penulisan jurnal yang banyak dibuat oleh komunitas orangtua muda.

Sementara Tita, menjelaskan bahwa "Menulis jurnal di buku adalah salah satu morning ritual, yang bermanfaat untuk merilis suara-suara berisik di pikiran. Setelahnya, jadi bisa fokus seharian." (Tita, 4 Juli 2021)

Baginya menulis jurnal sudah menjadi rutinitas yang membantuknya menjalani hari dengan lebih baik. Manfaat menulis jurnal lainnya juga dipaparkan oleh Uti sebagai Informan kedua

"Menulis jurnal menjadi solusi yang terbaik jika ingin mengeluarkan unek-unek atau curhat tentang sesuatu atau seseorang tanpa khawatir rahasia akan terbongkar ataupun rasa bersalah karena telah menjelek-jelekan orang lain." (Uti, 4 Juli 2021)

Menurut Uti informan keempat, menulis jurnal bisa melepeskan kegundahannya tanpa ada rasa bersalah karena bergunjing. Dapat dilihat dari pernyataan ini bahwa menulis jurnal adalah media komunikasi yang bisa dipercaya oleh sang pembuat pesan (sender).

Sementara Samantha, seorang pegawai kantor dan orangtua tunggal dari 1 anak balita perempuan memaparkan bahwa kegiatan menulis jurnal adalah caranya merilis penat. "Saya memang suka menulis jurnal karena sangat membantu relaksasi dalam menghadapi penatnya urusan pekerjaaan dan mengurus anak. Jurnal seperti pasangan yang selalu siap sedia mendengarkan keluh-kesah saya, dan saya sering ikut kelas pelitahan menulis ini secara daring." (Samantha, 5 Juli 2021)

Dari pernyataan informan kelima ini dapat dikatakan bahwa kegiatan analog menulis jurnal, hadir mengisi ruang kosong di kehidupannya sebagai orangtua tunggal yang tetap membutuhkan "teman dekat atau pasangan" yang mendengarkan segala cerita. Ia pun juga kerap mengikuti kelas pelatihan menulis jurnal yang banyak dibuat oleh komunitas keluarga muda.
Komunitas orangtua muda di kota-kota besar Indonesia, umumnya mulai mengenal konsep journaling dari fase kehamilan untuk menulis cerita-cerita dan pengalamanpengalaman calon ibu semasa hamil di tiap minggu tumbuh kembang janinnya. Contoh jurnal kehamilan yang ada adalah dari Nujuh Bulan Studio Childbirth Education Center, berikut:

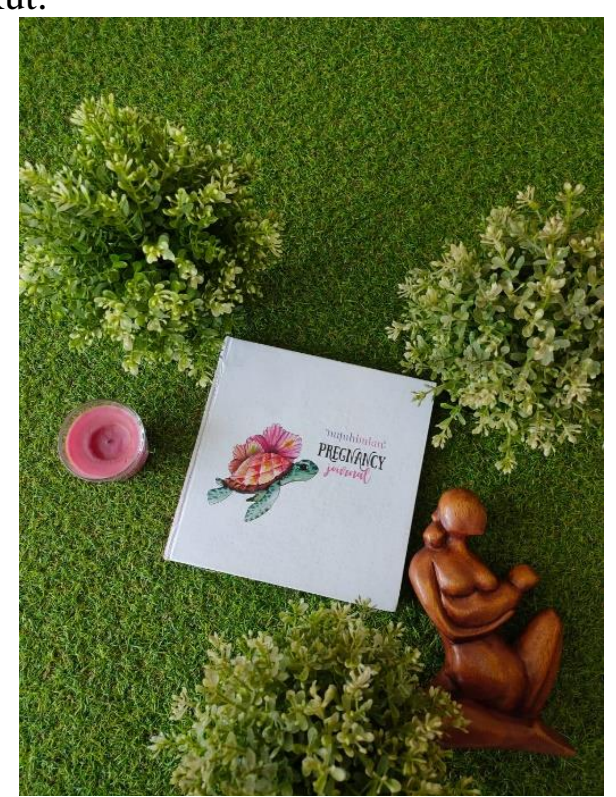

Gambar 2. Buku Jurnal Kehamilan dari Nujuh Bulan Childbirth Education Center

(Sumber: Tia Pratignyo dari nujuhbulan.com, 2021)

Setelah melalui fase kehamilan dan melahirkan, seorang perempuan akan menjadi Ibu. Peran baru ini juga menghadirkan dinamika kehidupan lain bagi perempuan. Kegiatan journaling pun hadir sebagai sebuah terapi berkesadaraan yang bisa Ibu lakukan guna merilis stres demi menjalani pola asuh kepada anak yang lebih baik.

Jurnal kehamilan ini menjadi salah satu terapi bagi ibu pasca melahirkan yang mengalami trauma saat proses dan setelah persalinan. Kegiatan journaling secara ilmiah mampu mirilis hormon stres saat menghadapi ingatan traumatis juga berkurang.

Memaparkan pikiran, peristiwa, dan perasaan yang pernah dan sedang dialami ke dalam bentuk tulisan, diyakini mampun meningkatkan kesejahteraan dan kesehatan mental. 


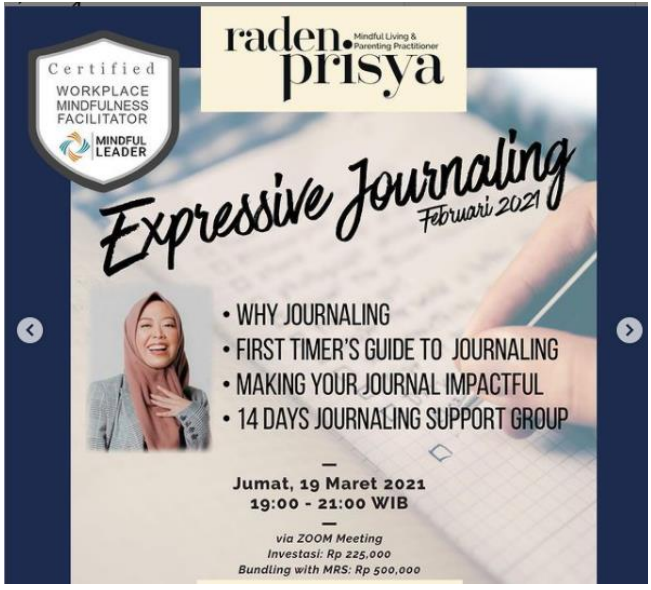

Gambar 3. Kegiatan menulis jurnal menjadi sebuah industri - Kelas Expressive Journaling. (Sumber: Instagram Raden Prisya, 2021)

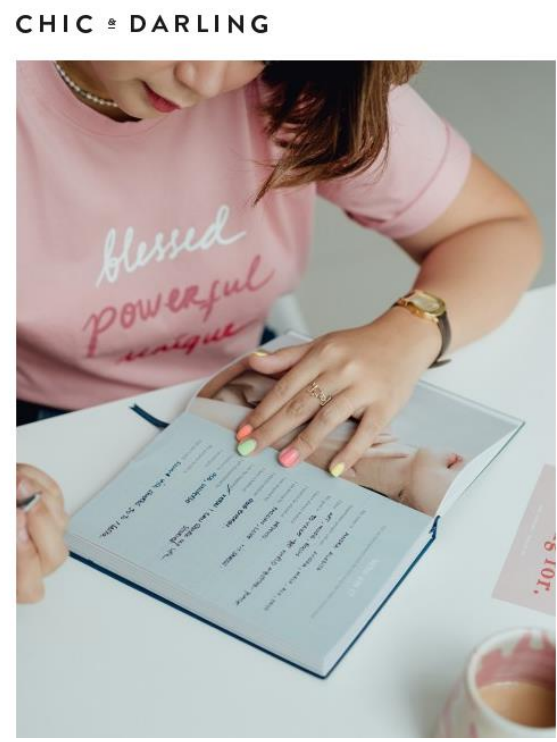

Dalam masyarakat informasi sekarang ini, journaling tidak hanya tumbuh menjadi sebuah terapi untuk mencapai kesehatan mental namun juga menjadi sebuah industri. Di mana banyak komunitas maupun individu momfluencer atau mommy influencer yang populer di ranah virtual mengadakan kelas pelatihan menulis jurnal ataupun memproduksi buku jurnal yang dijual ke komunitas perkumpulan ibu yang mereka kelola.

Dalam melakukan journaling, selain kemampung menulis, imajinasi juga memainkan peran bagi pelakunya. Karena secara visual, kegiatan menulis buku jurnal ini juga mendorong orang untuk menggambar, mewarnai, dan bermain dengan warna-warna pada alat tulis yang mereka pakai.

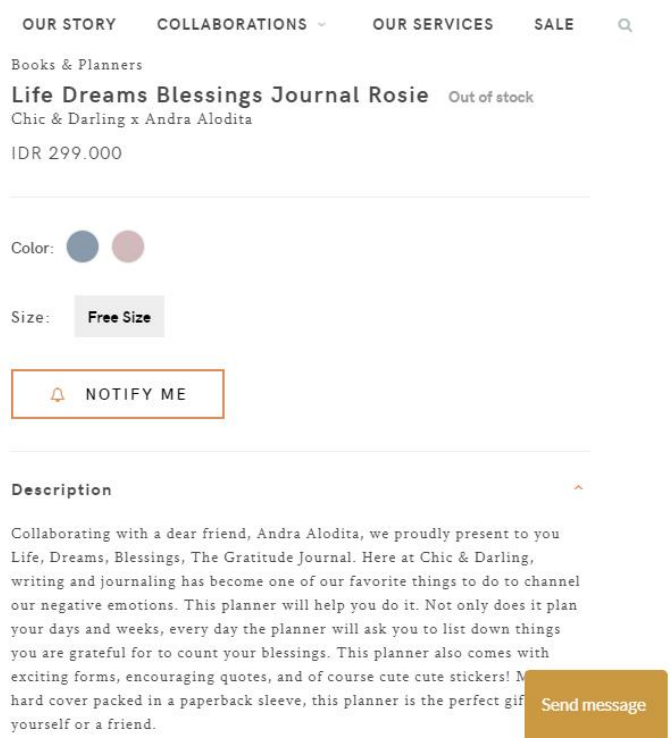

Gambar 4. Kegiatan menulis jurnal menjadi sebuah industri - sebuah retail online shop bekerjasama dengan influencer untuk menjual buku jurnal ke kalangan ibu muda

Sumber (Chicanddarling.com, 2020)

Journaling yang merupakan kegiatan komunikasi berbasis analog, tampil dengan pembaharuan dan revitalisasi bagi komunitas ibu muda di Indonesia yang tidak hanya sebagai medium untuk menulis pengalaman harian mereka sebagai seorang Ibu dan orangtua, namun juga menghidupkan roda bisnis bagi kalangan komunitas Ibu dan pelaku bisnis golongan UMKM (Usaha Mikro, Kecil, dan Menengah) yang kerap membuka kelas-kelas journaling dari berbagai tema dan juga memproduksi buku jurnal yang dikemas secara kreatif untuk dijual. 

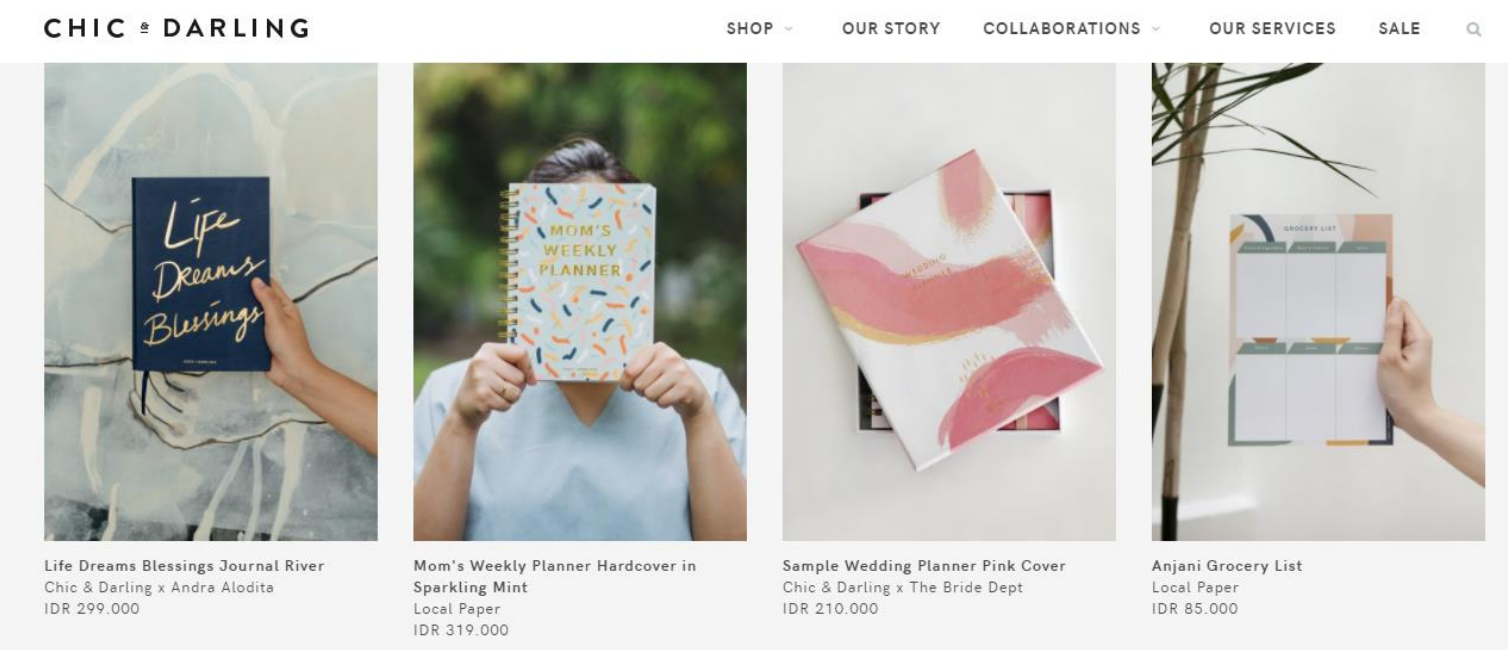

Gambar 5. Kegiatan menulis jurnal menjadi sebuah industri - ragam tipe buku jurnal yang dijual oleh pelaku UMKM ke kalangan ibu muda

(Sumber: Chicanddarling.com, 2020)

Buku jurnal yang dikemas secara kreatif untuk segmen ibu muda dari generasi millennial di kota besar Indonesia pun beragam bentuknya, ada jurnal khusus mencurahkan rasa syukur atau blessing journal, jurnal kegiatan harian dan mingguan atau mom's weekly planner, dan ada jurnal untuk berbelanja kebutuhan pangan dalam rumah tangga atau lebih populer disebut dengan grocery list journal.

Menulis tangan ke sebuah buku jurnal yang semula kegiatan ini hampir punah digerus oleh hadirnya teknologi digitalisasi, ternyata mampu menjadi sebuah konsep relaksasi yang menyegarkan dan bisa dikapitalisasi oleh pelaku bisnis dengan segmentasi market Ibu muda di kota-kota besar. Para pemain dalam industri journaling ini, sesungguhnya telah berhasil membuat pasar mereka. Dalam prespektif ilmu komunikasi, teknologi, dan masyarakat, pelaku dalam industri journaling ini mengkonstruksi sebuah kebutuhan komunikasi analog untuk relaksasi dan kesejahteraan mental bagi masyarakat khususnya Ibu dari golongan keluarga muda di Indonesia.

Ide menulis jurnal dengan kemasasan desain sampul dan halaman yang berwarna, mengategorikan jenis buku untuk beragam kebutuhan, dan elaborasi susunan kata yang bersifat populer dan afirmatif untuk menenangkan kaum ibu muda, menjadikan kegiatan menulis dengan tangan sebagai komunikasi analog yang terevitalisasi.

Kegiatan menulis jurnal yang dilakukan secara berkala untuk membangun pola hidup dan asuh yang berkesadaran menjadi bukti bahwa secara empiris dan akademisi, produk dari ilmu komunikasi bisa sangat bermanfaat untuk ilmu perilaku manusia atau psikologi.

Menulis buku secara analog atau journaling ini dapat digambarkan sebagai sebuah kajian ilmu interdispilin dan multidisplin antar ilmu komunikasi, ilmu bahasa, ilmu psikologi, dan kajian ilmu budaya.

\section{SIMPULAN}

Menulis dengan tangan adalah salah satu bentuk komunikasi termediasi yang pertama kali hadir di kehidupan manusia. Menulis tangan ke berbagai medium adalah sebuah kegiatan komunikasi analog yang sudah ada dari sejak zaman Bangsa Sumeria 35.000 SM. Menulis pada mulanya hadir sebagai cara berkomunikasi jarak jauh dalam ranah berniaga. Medium manusia dalam menuangkan tulisannya pun selalu berkemang, dimulai dari menulis di atas batu seperti yang bangsa Mesir kuno lakukan dengan pemahatan simbol-simol tulisan di dinding makam raja atau peti matinya, 
lalu menulis di lembaran-lembaran lempung (clay) yang dibakar, papyrus yang menjadi asal-muasal pengembangan kertas yang bisa kita jumpai sampai saat ini.

Berdasarkan temuan penelitian, dapat disimpulkan bahwa fenomena menulis jurnal yang dihadirkan dalam komunitas-komunitas keluarga di Indonesia adalah sebuah kegiatan komunikasi analog yang memiliki karakteristik relaksasi ataupun terapik bagi para orangtua. Menulis di buku jurnal menjadi sebuah kegiatan komunikasi termediasi yang memiliki nilai privasi dan etika dibandingkan menulis jurnal dalam bentuk blog atau media digital lainnya yang mudah diakses oleh orang lain. Hal-hal inilah yang membuat kegiatan menulis secara analog di buku menjadi sebuah aktivitas yang berhasil terevitalisasi dan digandrungi. Di tengah kehadiran teknologi informasi berbasis digital yang masif, di Indonesia kegiatan menulis dengan tangan di dalam medium kertas justru mendapatkan ruang sebagai sebuah ide yang menyegarkan untuk kalangan orang tua dari generasi Millenial.

Penulis sangat merekomendasikan untuk adanya penelitian yang lebih lanjut, komprehensif dan mendalam seputar kegiatan journaling sebagai sebuah kegiatan komunikasi yang tidak hanya bermanfaat untuk kesehatan mental kaum ibu muda dari generasi Millenial, yang bisa dikaji melalui Fenomenologi ataupun dengan pendekatan Kuantitatif. Selain itu, ada baiknya juga dilakukan penelitian komunikasi dari kegiatan journaling sebagai alat atau tools untuk melatih dan meningkatkan kesehatan mental bagi generasi Millenial dalam pola dikdik anak-anak generasi Alpha. Dari penelitian ini hasilnya bisa dikemukan bahwa pada penerapan Ilmu Komunikasi dan pengaplikasiannya sangatlah bermanfaat untuk ilmu-ilmu lainnya.

Bagi para praktisi dunia Komunikasi, baik komunikator ataupun pelaku bisnis di Industri ini, kebangkitan komunikasi analog melalui ide dan kegiatan menulisi tangan yang direvitalisasi menjadi journaling ini adalah sebuah realitas yang ada di tatanan masyarakat, bahwa selalu kreatif mencari celah dan mengolah sebuah medium komunikasi. Praktisi harus selalu peka dengan segala manfaat medium komunikasi yang bisa dilihat dari banyak dimensi, dalam hal journaling yang paparkan dalam tulisan ini dapat dilihat bahwa Ilmu Komunikasi sangat bermanfaat untuk kesehatan mental kaum ibu muda di kota besar yang rawan stres. Tugas para praktisi komunikasi tidak hanya menguasai perkembangan teknologi informasi, namun juga mempertahakan dan menciptakan sebuah ide dari medium komunikasi yang hampir punah namun ternyata memiliki banyak manfaat untuk masyarakat.

\section{DAFTAR PUSTAKA}

Allan, D. (2015). On Technological Determinism: A Typology, Scope Conditions, and a Mechanism. Science, Technology, \& Human Values. doi:https://doi.org/10.1177/016224391 5579283

Brocke, J. B., \& de Marco, M. (2016, May). The Networked Society. Bus Inf Syst Eng.

doi:https://doi.org/10.1007/s12599016-0434-4

Bungin, B. (2015). Analisis Data Penelitian Kualitatif. Jakarta: Raja Grafindo Persada.

Bute, J., Comer, K., Lauten, K., Sanematsu, H., Moore, C., Lynch, D., \& Chumbler, N. (2014). Implementation of a Journal Prototype for Pregnant and Parenting Adolescents. Evaluation and Program Planning. ResearchGate. Retrieved from

https://www.researchgate.net/publicati on/262807832_Implementation_of_a_J ournal_Prototype_for_Pregnant_and_P arenting_Adolescents/citation/downloa d

chicanddarling.com. (2020). Retrieved from chicanddarling.com:

https://chicanddarling.com/blog/aconversation-with-andra-alodita-onbeing-grateful-for-the-little-things-inlife-UrJvs 
Chicanddarling.com.

(2020).

chicanddarling.com. Retrieved from https://chicanddarling.com/shop/life-

dreams-blessings-journal-

DoaWp?var=life-dreams-blessingsjournal-rosie-IBxjW

Dailymail.uk. (2012, June 22). Retrieved from Dailymai.uk:

https://www.dailymail.co.uk/sciencetec h/article-2163175/Could-forget-

WRITE-The-typical-adult-scribbledhand-weeks.html

Ewan, C. (2019). www.bl.uk. Retrieved from www.bl.uk: https://www.bl.uk/historyof-writing/articles/where-did-writingbegin\#

Griffin, E., Ledbetter, A., \& Sparks, G. (2019). A First Look at Communication Theory. New York, New York: McGraw-Hill Education.

Hakiki, T. (2015). Komitmen Beragama pada Muallaf (Studi Kasus pada Muallaf Usia Dewasa). Jurnal Kesehatan Klinis dan Kesehatan Mental Universitas Airlangga Surabaya.

Kiefer, M., Schuler, S., Hofmann, C., Trumpp, N., Hille, K., \& Sachse, S. (2015). Handwriting or Typewriting? The Influence of Penor Keyboard-Based Writing Training on Reading and Writing Performance in Preschool Children. Advance in Cognitive Psychology. ResearchGate. Retrieved from

https://www.researchgate.net/publicati on/284277327_Handwriting_or_Type writing_The_Influence_of_Penor_Key board-

Based_Writing_Training_on_Reading_ and_Writing_Performance_in_Prescho ol_Children

Kompas.com. (2020, Maret 15). Retrieved from

Kompas.com:

https://www.kompas.com/skola/read/2

020/03/15/150000269/sejak-kapan-

menulis-dilakukan-?page=all\#page 2

Littlejohn, W. S., Foss, A. K., \& Oetzel, G. J. (2017). Theories of Human
Communication Elevent Edition. Long Grove, IL: Waveland Press, Inc.

Manly, C. (2021). Dr Carla Manly Clinical Psychologist. Retrieved from https://drcarlamanly.com/

McLuhan, M. (2013). Understanding The Media: Extension of A Man. Ginko Press, Incoporated.

Medwell, J., \& Wray, D. (2017). What's the use of handwriting?: a white paper. ResearchGate. Retrieved from https://www.researchgate.net/publicati on/319537899_What's_the_use_of_han dwriting_a_white_paper/citation/downl oad

Moleong, J. L. (2018). Metodologi Penelitian Kualitatif Cetakan ke-38. Bandung: PT Remaja Rosdakarya.

mommiesdaily.com. (2020, Oktober 6). mommiesdaily.com. Retrieved from mommiesdaily.com:

https://mommiesdaily.com/2020/10/06/ journaling-kegiatan-nostalgiasekaligus-menjaga-kesehatan-mental/

Nakano, D., \& Muniz, J. (2018). J. Writing the literature review for empirical papers. doi:https://doi.org/10.1590/01036513.20170086

Nur'ain, D. R. (2020). PENERAPAN METODE STUDI KASUS YIN DALAM PENELITIAN. Jurnal Universitas Negeri Yogyakarta.

Olson, D. R. (2020). Writing. Encyclopedia Britannica. Britannica. Retrieved from https://www.britannica.com/topic/writi ng

Pinch, J., Hughes, T., \& Bijker, E. W. (2014). The Social Construction of Technological Systems: New Directions in the Sociology and History of Technology (Fourth Pri, Vol. 086). doi:https://doi.org/10.1017/CBO97811 07415324.004

Popbela.com. (2021). Retrieved from Popbela.com:

https://www.popbela.com/beauty/healt h/gita-laras-widyaningrum/manfaatjournaling-bagi-kesehatan/2 
Pratignyo, T. (2021). nujuhbulan.com. Retrieved from nujuhbulan.com: www.nujuhbulan.com

Prisya, R. (2021). Instagram. Retrieved from https://www.instagram.com/p/CL6qOkA1ro/

Purcell, M. (2014, May 2). The Health Benefits of Journaling. Session 7 - Article - The Benefits of Journaling, pp. 1-2. Retrieved from https://communityofmindfulparenting.c om/curriculum/week7/S7-ArticlesTheHealthBenefitsofJournaling.pdf

Ratna, D. I. (2017). PENINGKATAN KEMAMPUAN MENULIS PUISI. Jurnal Diksatrasa, 97.

Ridley, D. (2012). The literature review a stepby-step guide for students (2nd Edition). London: Sage Pub. London: Sagepub.

Setyowati, Y. (2013). Pola Komunikasi Keluarga dan Perkembangan Emosi Anak (Studi Kasus Penerapan Pola Komunikasi Keluarga dan Pengaruhnya Terhadap Perkembangan Emosi Anak pada Keluarga Jawa). media.netliti.

Straubhaar, J., LaRose, R. L., \& Davenport, L. (2016). Media Now : Understanding Media, Culture, and Technology Ninth Edition. Boston, MA: Cencage Learning.

Straubhaar, J., Tufekci Zeyned, S. J., \& Rojas, V. (2012). Digital inequity in the Austin technopolis--An Introduction.. Austin: University of Texas.

Sujarweni, A. W. (2014). Metodologi Penelitian. Yogyakarta: Pustaka Baru. thewashingtonpost.com. (2013, April 4). thewashingtonpost.com. Retrieved from thewashingtonpost.com: https://www.washingtonpost.com/local /education/cursive-handwritingdisappearing-from-publicschools/2013/04/04/215862e0-7d2311e2-a044-676856536b40_story.html

Thoele, D., Gunalp, C., \& Baran, D. (2020). ealth care practitioners and families writing together: The Three Minute Mental Makeover. www.thepermanentejournal.org. doi:https://doi.org/10.7812/TPP/19.056 Tsabary, S. (2016, March 27). drshefali.com. Retrieved from drshefali.com: https://www.drshefali.com/5-profoundlife-lessons/

Vann, R. T. (2020, October 27). Historiography .Encyclopedia Britannica. Retrieved from

https://www.britannica.com/topic/histo riography

www.worldhistory.org. (2011). Retrieved from www.worldhistory.org: https://www.worldhistory.org/writing/

Xiao, Y., \& Watson, M. (2017). . Guidance on Conducting a Systematic Literature Review. Journal of Planning Education and Research. Retrieved from https://www.researchgate.net/publicati on/319343044_Guidance_on_Conducti ng_a_Systematic_Literature_Review

Yin, K. R. (2015). Case Study Research Design and Methods (5th ed.). Thousand Oaks, CA: Sage. 